\title{
Динамика массы и состава древесного опада в сосняке Лапландского заповедника
}

\author{
Иванова Е.А., Исаева Л.Г. \\ Институт проблем промышленной экологии Севера ФИЦ КНЦ РАН, Anamumbl, ivanova@inep.ksc.ru
}

\begin{abstract}
Аннотация. Изучена динамика массы и фракционного состава древесного опада в сосняке кустарничковолишайниковом Лапландского заповедника в зоне влияния воздушного загрязнения медно-никелевого комбината «Североникель». Опад характеризуется значительной временной (сезонная и многолетняя динамика) и пространственной (подкроновые и межкроновые пространства) изменчивостью по размерам и фракционному составу. Основная масса опада формируется в теплый период года (июнь-сентябрь). За 23-летний период наблюдений выявлены тренды увеличения массы опада, главным образом, за счет хвои и коры сосны, несмотря на снижение объемов выбросов, что может быть обусловлено ослаблением деревьев, вызванным длительным влиянием атмосферного загрязнения на лесные экосистемы, увеличением возраста и фитомассы древостоя. Учет значительной внутрибиогеоценотической изменчивости формирования опада позволит давать более точные оценки динамики органического вещества и циклов элементов в северотаежных лесах.

Ключевые слова: древесный опад, сосновый лес, Лапландский заповедник, аэротехногенное загрязнение, фракционный состав, пространственное варьирование, сезонная и многолетняя динамика.
\end{abstract}

\section{Mass and structure dynamics of litterfall in a pine forest of the Lapland Reserve}

\author{
Ivanova E.A., Isaeva L.G. \\ Institute of the Industrial Ecology Problems of the North KSC RAS, Apatity, ivanova@inep.ksc.ru
}

\begin{abstract}
The mass and fractional composition dynamics of litterfall in pine forests of shrub-lichens in the Lapland Reserve subjected to industrial air pollution by emissions of the copper-nickel combine «Severonikel» were investigated. Stand litterfall was characterized by significant temporal (seasonal and long-term) and spatial (belowand between the crowns) variation in the quantity and fractional composition. Most of the litter is formed during the warm season (June-September). Over the 23-year observation period the litterfall amount tends to increase mainly by needles and bark despite the reduction of emissions, which is explained by weakening of the trees caused by the long-term influence of aerial pollution at forest ecosystems, and by increasing age and biomass of forest stand. It is important to take into account considerable intra-biogeocenotic variability of formation litter to give more accurate estimates of the organic matter dynamics and the cycles of elements in northern taiga forests.
\end{abstract}

Key words: tree litter, pine forest, Lapland Reserve, aerial pollution, fractional composition, spatial variation, seasonal and long-term dynamics.

\section{Введение}

Основу общего опада в северотаежных лесах составляет древесный опад - один из важнейших компонентов биогеохимических циклов в лесных экосистемах (Никонов, Лукина, 1994). Количество и структурный состав опада зависят от состава древостоя, годичного прироста деревьев, их возраста, климатических условий и др. (Pedersen, Bille-Hansen, 1999). В таежных лесах европейской части России и за рубежом в разные годы проводились масштабные работы по оценке массы и фракционного состава опада (Манаков, Никонов, 1981; Berg et al., 1999 и др.), исследовалась сезонность поступления древесного опада (Цветков В., Цветков И., 2003).

Развитие промышленности, рост населения и расширение городов привели к быстрому возрастанию негативных техногенных воздействий на леса. Вокруг промышленных предприятий отмечалась гибель насаждений, прежде всего хвойных (Цветков, Сизов, 1991). Воздушное загрязнение приводило к изменениям динамики количественных показателей и структуры поступающего опада (Юсупов и др., 1995), повреждения ассимилирующего аппарата хвойных древесных растений кислотными осадками вызывали дефолиацию деревьев не только в фенологические сроки, что способствовало увеличению количества опада (Лукина, Никонов, 1998; Ярмишко, Лянгузова, 2013). 
На территории Кольского полуострова сложные климатические условия усугубляются антропогенным влиянием со стороны предприятий металлургического производства. Комбинат «Североникель» (АО «Кольская ГМК») в г. Мончегорск - крупнейший источник выбросов $\mathrm{SO}_{2}$ и полиметаллической пыли в центральной части региона, где также расположен Лапландский государственный природный биосферный заповедник. В 1990-е годы в результате экономического кризиса и благодаря мероприятиям по оптимизации производства произошло значительное снижение выбросов вредных веществ, объем валовых выбросов $\mathrm{SO}_{2}$ снизился с 232.5 в 1990-м до 33.5 тыс. т/год в 2014 году (данные АО «Кольская ГМК»). Цель данной работы - оценить на основе многолетних данных динамику массы и фракционного состава древесного опада в сосняке кустарничково-лишайниковом на территории Лапландского заповедника в период снижения техногенной нагрузки.

\section{Методика}

Исследования проводились в период 1995-2018 гг. на стационарной мониторинговой площадке на территории Лапландского заповедника в сосновом кустарничково-лишайниковом лесу. Площадка входит в сеть биогеохимического мониторинга, которая была создана в 1990-х гг. под руководством профессора, доктора биологических наук В.В. Никонова, и расположена в зоне влияния выбросов медно-никелевого комбината «Североникель» (г. Мончегорск) в ЮЮЗ направлении от него на расстоянии 30 км. По классификации основных типов лесов Севера в индустриальноразвитых регионах (Лукина, Никонов, 1998) исследуемый сосняк относится к стадии дефолиирующих лесов. В составе древостоя присутствует береза и единично встречается ель. Леса подвергались в прошлом действию пожаров.

В соответствии с рекомендациями международной программы ICP-Forests (Ukonmaanaho et al., 2015) для сбора опада используются воронковидные коллекторы (опадоуловители) с прикрепленными к ним мешочками из хлопчатобумажной ткани (рис. 1). В 1994 г. коллекторы были

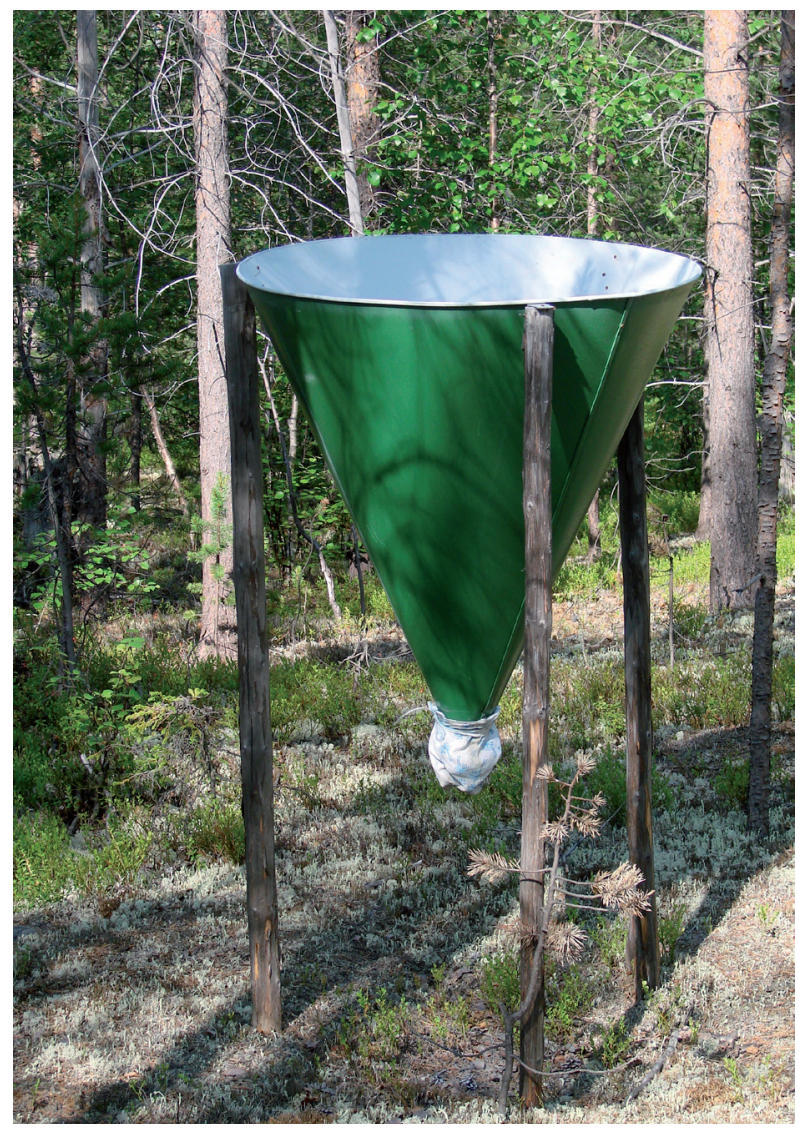

Рис.1. Коллектор для сбора опада (опадоуловитель). Fig. 1. Collector for sampling litter (litter trap). установлены случайным образом преимущественно в межкроновых пространствах, а с 2013 г. для выявления пространственных особенностей в составе и количестве древесного опада - в межкроновых и подкроновых пространствах. По состоянию на 2018 г. на площадке в Лапландском заповеднике в межкроновых пространствах установлено 8 опадоуловителей, в подкроновых - 5. Древесный опад собирался круглогодично, отбор образцов проводился дважды в год: в первой декаде октября и первой декаде июня. При отборе пробы с коллектора в каждый мешочек помещалась бирка с номером площадки, номером опадоуловителя и обозначением сезона, за который поступил опад.

В лабораторных условиях опад тщательно разбирался на фракции (хвоя, кора, ветки, шишки, микростробилы, семена сосны, листья березы, хвоя ели, семена березы, листья ивы, эпифитные лишайники и др.), каждая из фракций затем взвешивалась. Для расчета абсолютно сухого веса бралась навеска по 1 г каждой фракции и высушивалась в сушильном шкафу при температуpe $105^{\circ} \mathrm{C}$ с последующим взвешиванием. Полученные данные обрабатывались с помощью программного обеспечения MS Excel и Statistica. 
Особенности пространственного распределения опада оценивали за период 2014-2018 гг. с использованием результатов картирования проективного покрытия крон деревьев, проведенного в 2015 г. На стационарной площадке были выделены три участка прямоугольной формы площадью

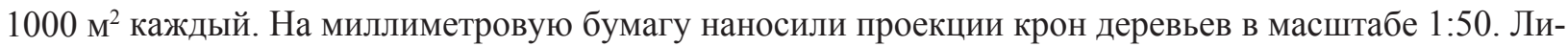
сты с данными картирования были отсканированы и сведены с помощью графического редактора Paint.NET в карты-схемы проективного покрытия крон деревьев. Подсчет площадей выполнялся с помощью графического анализатора ImageJ по картам-схемам. Расчет массы фракций опада с учетом пространственного варьирования выполнялся путем умножения значения измеренной массы в кг/га на долю пространств от общей площади, выраженную в процентах, и деления полученного результата на 100 \%. Рассчитанные отдельно друг от друга значения для подкроновых и межкроновых пространств суммировались для получения того значения массы, которое поступает на 100 \% площади.

\section{Результаты}

Для оценки многолетней динамики, среднегодовых и сезонных параметров состава опада за период 1995-2018 гг. использовались данные по массе опада при случайном расположении опадоуловителей до 2013 года, а после 2013 - только по межкроновым. Анализ данных показал, что общая масса опада в сосняке кустарничково-лишайниковом в Лапландском заповеднике в исследуе-
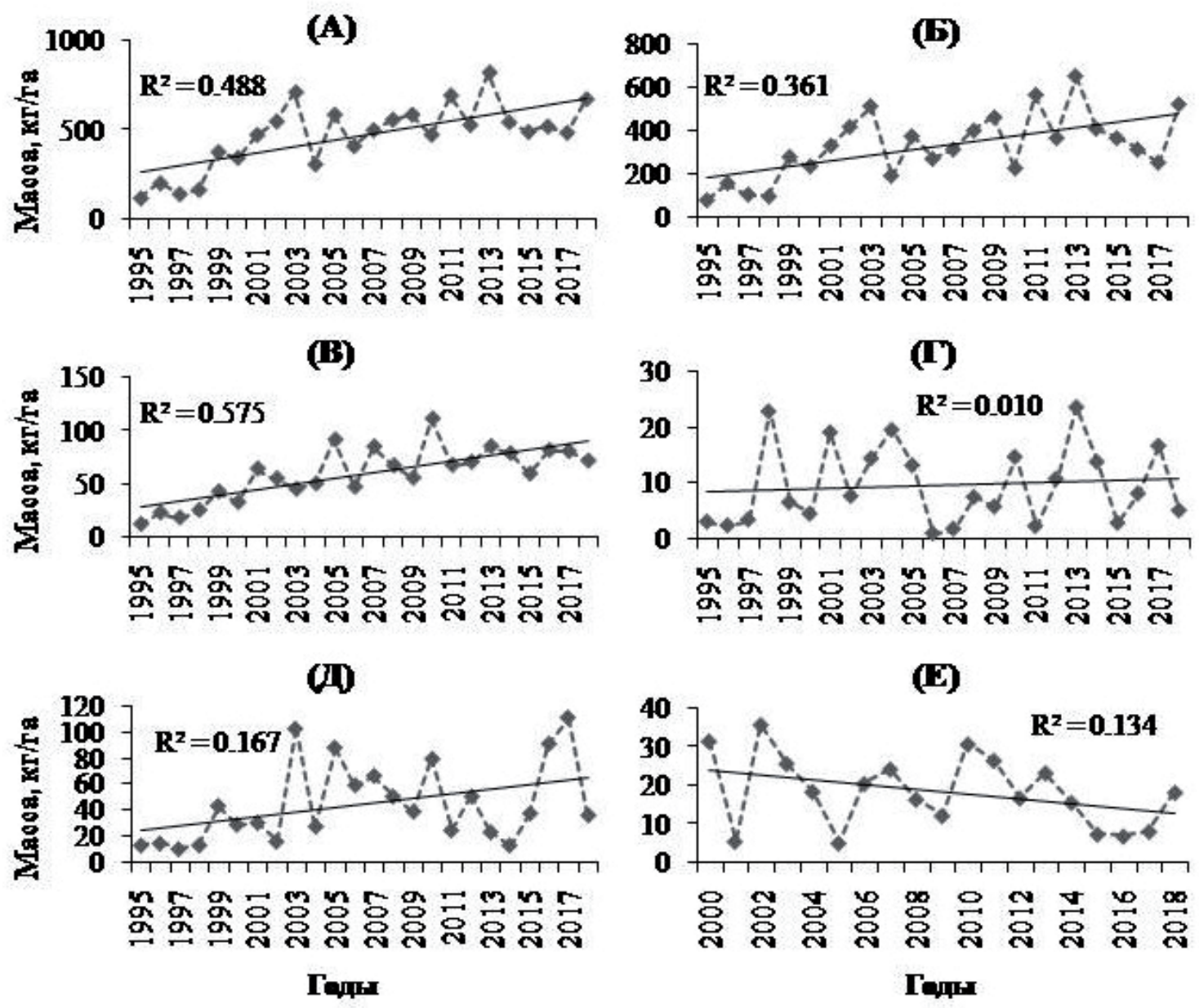

Рис. 2. Динамика общей массы опада и основных его фракций за период 1995-2018 гг., буквами на рисунке обозначены: А - общий опад, Б - опад хвои сосны, В - опад коры сосны, Г - ветки $(\mathrm{d}<1 \mathrm{~cm})$, Д - генеративные органы сосны (суммарный опад шишек, семян и микростробил сосны), Е - опад листьев березы.

Fig. 2. The dynamics of the total mass of litter and its main fractions over the period 1995-2018, the letters in the figure are: $\mathrm{A}$ - total litter, $\mathrm{B}$ - pine needles litter, $\mathrm{C}$ - pine bark litter, $\mathrm{D}$ - branches $(\mathrm{d}<1 \mathrm{~cm}), \mathrm{E}$ - pine generative organs (total litter of cones, seeds and pollen cones), $\mathrm{F}-$ birch leaves litter. 
мый период варьировала от 120.2 до 816.9 кг/га в год. По среднегодовым значениям большую часть древесного опада составляют хвоя (69 \%), кора (13\%) и шишки сосны (8 \%), значительна доля листьев березы (4 \%). Меньшим вкладом характеризуются ветки и микростробилы сосны. Единично в опадоуловители попадали сережки березы, хвоя ели, семена березы и сосны.

Количество поступающего древесного опада проявляет сезонность: доля общей массы опада периода «июнь-сентябрь» от годового поступления опада составила в среднем 75 \%, периода «октябрь-май» - $25 \%$. Преобладание тех или иных фракций в опаде также проявляет сезонность. Основу древесного опада холодного периода года составляют хвоя (74.1 кг/га, 64 \%), кора (21.1 кг/ га, 20 \%) и шишки сосны (8.4 кг/га, 7 \%), теплого - хвоя (255.4 кг/га, 71 \%), кора (38.8 кг/га, 11 \%), шишки сосны (30.0 кг/га, 9 \%) и листья березы (16.1 кг/га, 4 \%). Помимо хвои и шишек сосны а также листьев березы, в «летнем» опаде доля микростробил выше, чем в зимнем (2 и $0.4 \%$, соответственно). В холодный период года доля коры и ветвей сосны больше, чем в теплый, что, возможно, связано с погодными особенностями - ветви могут обламываться под снеговыми массами.

Анализ данных по многолетней динамике массы опада за период 1995-2018 гг. показал четкие тенденции к увеличению общей массы опада, а также основных его фракций (хвоя и кора сосны) (рис. 2). Увеличение количества опада в период снижения атмосферных выбросов может быть связано, с одной стороны, с ослаблением деревьев и преждевременным отмиранием отдельных органов, вызванными многолетним воздействием загрязнения, а с другой стороны, с повышением возраста и фитомассы древостоев.

Пространственные особенности распределения опада оценивались для периода 2014-2018 гг. с использованием данных о проективном покрытии крон деревьев. По результатам картирования доля площадей подкроновых пространств составила 53 \%, межкроновых - 47 \%. При этом и суммарная масса всех компонентов древесного опада подкроновых пространств была достоверно $(\mathrm{p}<0.05)$ больше, чем в межкроновых пространствах древостоя, в среднем разница составила 4 раза. Достоверные различия можно отметить также для коры, веток и шишек сосны. По общей массе под кронами преобладает хвоя сосны (50 \%), меньше - коры (17 \%), шишек (14 \%) и ветвей (13\%). В межкроновых пространствах наблюдается значительное количество хвои (69 \%) по сравнению с другими фракциями. Следует отметить, что доля хвои в общем опаде межкроновых пространств больше, чем подкроновых, но по средним значениям массы между кронами деревьев хвои опадало значительно меньше, чем под кронами (167.5 и 521.3 кг/га, соответственно). Поскольку для распределения древесного опада характерна значительная пространственная изменчивость, ее необходимо учитывать для более точной оценки динамики органического вещества и циклов элементов в северотаежных лесах.

\section{Заключение}

Древесный опад в сосняке кустарничково-лишайниковом в Лапландском заповеднике в зоне влияния комбината «Североникель» характеризуется значительным временным и пространственным варьированием по размерам и по фракционному составу. Основная масса опада формируется в теплое время года (июнь-сентябрь). В период 1995-2018 гг. выявлены тренды увеличения массы опада, главным образом, за счет хвои и коры сосны, несмотря на снижение объемов выбросов, что может быть связано с ослаблением деревьев, вызванным длительным влиянием атмосферного загрязнения на лесные экосистемы, увеличением возраста и фитомассы древостоя. Пространственные особенности распределения опада характеризуются значительной изменчивостью, поступление опада преобладает под кронами деревьев, при этом доля опадающей хвои выше между крон, что необходимо учитывать при расчетах для более точной оценки динамики органического вещества и циклов элементов в северотаежных лесах.

Работа выполнена в рамках темы НИР №AААА-А18-118021490070-5. 


\section{Литература}

1. Лукина Н.В., Никонов В.В. Питательный режим лесов северной тайги: природные и техногенные аспекты. Апатиты: Изд-во КНЦ РАН. 1998. 316 с.

2. Манаков К.Н., Никонов В.В. Биологический круговорот минеральных элементов и почвообразование в ельниках Крайнего Севера. Л.: Наука. 1981. 196 с.

3. Никонов В.В., Лукина Н.В. Биогеохимические функции лесов на северном пределе распространения. Апатиты: Изд-во КНЦ РАН. 1994. 315 с.

4. Цветков В.Ф., Сизов И.И. Хозяйственно-экологическая характеристика нарушенных земель в зоне деятельности комбината «Североникель» / Экологические исследования в лесах Европейского Севера. Архангельск. 1991. С. 111-124.

5. Цветков В.Ф., Цветков И.В. Лес в условиях аэротехногенного загрязнения. Архангельск: Кн. изд-во. 2003. $354 \mathrm{c.}$

6. Юсупов И.А., Залесов С.В., Шавнин С.А., Луганский Н.А. Особенности динамики и структуры древесного опада в сосновых молодняках в зоне действия аэропромвыбросов на Среднем Урале // Леса Урала и хозяйство в них: сб. науч. тр. Екатеринбург: Изд-во УГЛТА. 1995. Вып. 18. С. 59-74.

7. Ярмишко В.Т., Лянгузова И.В. Многолетняя динамика параметров и состояния хвои Pinus sylvestris L. в условиях аэротехногенного загрязнения на Европейском Севере // Известия СПбЛТА. 2013. № 2 (203). C. $30-46$.

8. Berg B., Albrektson A., Berg M. P., Cortina J., Johansson M-B., Gallardo A., Mgadeira M., Pausas J., Kiratz W., Vallejo R., McClaugherty C. Amounts of litter fall in some pine forests in European transect, in particular Scots pine // Annals of Forest Science. 1999. V. 56. P. 625-639.

9. Pedersen L. B., Bille-Hansen J. A comparison of litterfall and element fluxes in even aged Norway spruce, sitka spruce and beech stands in Denmark // For. Ecol. Manage. 1999. V. 114. P. 55-70.

10. Ukonmaanaho L., Pitman R, Bastrup-Birk A, Breda N, Rautio P. Manual on methods and criteria for harmonized sampling, assessment, monitoring and analysis of the effects of air pollution on forests. Part XIII Sampling and Analysis of Litterfall. UNECE ICP Forests Programme Co-ordinating Centre. Eberswald. 2015. 17 p. 